\title{
Variations of Kelvin waves around the TTL region during the stratospheric sudden warming events in the Northern Hemisphere winter
}

\author{
Yue Jia ${ }^{1,2,3}$, Shao Dong Zhang ${ }^{1,2,3}$, Fan Yi ${ }^{1,2,3}$, Chun Ming Huang ${ }^{1,2,3}$, Kai Ming Huang ${ }^{1,2,3}$, Yun Gong ${ }^{1,2,3}$, and \\ Quan Gan ${ }^{1,2,3}$ \\ ${ }^{1}$ School of Electronic Information, Wuhan University, Wuhan, China \\ ${ }^{2}$ Key Laboratory of Geospace Environment and Geodesy, Ministry of Education, Wuhan, China \\ ${ }^{3}$ State Observatory for Atmospheric Remote Sensing, Wuhan, China
}

Correspondence to: Shao Dong Zhang (zsd@whu.edu.cn)

Received: 9 October 2015 - Revised: 4 March 2016 - Accepted: 8 March 2016 - Published: 17 March 2016

\begin{abstract}
Spatial and temporal variabilities of Kelvin waves during stratospheric sudden warming (SSW) events are investigated by the ERA-Interim reanalysis data, and the results are validated by the COSMIC temperature data. A case study on an exceptionally large SSW event in 2009, and a composite analysis comprising 18 events from 1980 to 2013 are presented. During SSW events, the average temperature increases by $20 \mathrm{~K}$ in the polar stratosphere, while the temperature in the tropical stratosphere decreases by about $4 \mathrm{~K}$. Kelvin wave with wave numbers 1 and 2, and periods 1020 days, clearly appear around the tropical tropopause layer (TTL) during SSWs. The Kelvin wave activity shows obvious coupling with the convection localized in the India Ocean and western Pacific (Indo-Pacific) region. Detailed analysis suggests that the enhanced meridional circulation driven by the extratropical planetary wave forcing during SSW events leads to tropical upwelling, which further produces temperature decrease in the tropical stratosphere. The tropical upwelling and cooling consequently result in enhancement of convection in the equatorial region, which excites the strong Kelvin wave activity. In addition, we investigated the Kelvin wave acceleration to the eastward zonal wind anomalies in the equatorial stratosphere during SSW events. The composite analysis shows that the proportion of Kelvin wave contribution ranges from 5 to $35 \%$ during SSWs, much larger than in the non-SSW mid-winters (less than $5 \%$ in the stratosphere). However, the Kelvin wave alone is insufficient to drive the equatorial eastward zonal wind anomalies during
\end{abstract}

the SSW events, which suggests that the effects of other types of equatorial waves may not be neglected.

Keywords. Meteorology and atmospheric dynamics (middle atmosphere dynamics; waves and tides)

\section{Introduction}

Atmospheric Kelvin waves were first suggested by Matsuno (1966), and they are confined in the latitude range between $20^{\circ} \mathrm{S}$ and $20^{\circ} \mathrm{N}$ with no meridional components (Andrews et al., 1987). They are eastward propagating equatorial waves excited by tropical convection (Bergman and Salby, 1994), and are the most prominent components of the equatorially trapped wave mode of the temperature field (Tindall et al., 2006; Ern et al., 2008).

It was extensively accepted that the Kelvin waves are crucial in dynamic processes of equatorial atmosphere. They interact with the wind and play an important role in driving tropical quasi-biennial oscillation (QBO) by dissipation and transfer of momentum (Holton and Lindzen, 1972; Kawatani et al., 2009; Wallace and Kousky, 1968). Tropical tropopause layer (TTL) variability is also associated with Kelvin waves. Using simulations and global observational data, Ryu et al. (2008) found that the vertically propagating Kelvin waves play a pivotal role in the tropical tropopause height variability. Kelvin waves are also known in affecting the distribution of water vapor and the formation of clouds in the TTL region (Fujiwara et al., 2001; Zhou and Holton, 2002; Eguchi 
and Shiotani, 2004; Fueglistaler et al., 2009), even TTL upwelling is linked to the Kelvin waves (Ryu and Lee, 2010). Besides, Kelvin waves with shorter periods can propagate into the thermosphere and the ionosphere and then affect neutral and electron densities (Takahashi et al., 2007; Chang et al., 2010). More interestingly, Phanikumar et al. (2014) revealed ultra-fast Kelvin wave signatures in ionosphere during the polar stratospheric sudden warming (SSW) event in 2009, suggesting certain connections between Kelvin waves and SSWs.

Both spatial and temporal variations of the Kelvin waves have been investigated in detail by previous studies. Randel and $\mathrm{Wu}$ (2005) investigated the vertical variability of Kelvin waves and found that the maximum amplitudes of Kelvin waves were located near the tropopause. Alexander et al. (2008) and Suzuki et al. (2010) studied the longitudinal variability of Kelvin waves and suggested that some waves originated from the western hemisphere and propagated upward and eastward to South America. Alexander et al. (2008) also distinguished the monthly variability of Kelvin waves in 2007, and the strength of Kelvin wave was found to increase from February to March and suppress during September and October. Venkat Ratnam et al. (2006) discussed the annual variations of Kelvin wave activities, and reported that the maximum Kelvin wave strength was almost always observed in the Northern Hemisphere winter. Ern and Preusse (2009) calculated the Kelvin wave accelerations to the QBO and stated that peak accelerations accorded with the westerly shear phase. However, few attentions were paid to the variations of Kelvin waves during SSW events, even though hemispherical connections between these two phenomena have been notified.

The SSW is recognized as one of the most violent atmospheric phenomena, during which the temperatures in the polar stratosphere increase rapidly within a few days (Andrews et al., 1987). It affects the polar stratospheric thermal structure and circulation profoundly, and also has significant impacts on the regions from the troposphere to the thermosphere (Baldwin and Dunkerton, 2001; Liu and Roble, 2002; Thompson et al., 2002; Gong et al., 2013).

In addition to those influences on the polar atmosphere of the winter hemisphere, its associated effects could extend to the lower latitudes, affecting the dynamics from the tropical stratosphere (Manney et al., 2008) to the mesosphere and lower thermosphere (MLT) region (Sathishkumar et al., 2009; Lima et al., 2012), and even ionosphere (Jin et al., 2012; Gong et al., 2013). Fritz and Soules (1970) first revealed the lower temperature in the tropical stratosphere during an SSW event by satellite data. Several subsequent studies, both theoretical and observational, investigated the relationship between the tropical region and the SSW events (Garcia, 1987; Holton et al., 1995; Plumb and Eluszkiewicz, 1999; Randel et al., 2002; Vineeth et al., 2010; Yoshida and Yamazaki, 2011). These studies stated that the meridional circulation driven by the transient planetary wave forc- ing associated with polar SSWs can induce upwelling in the tropical region, in turn produce cooling in the stratosphere and upper troposphere in the tropical region during SSW events. Kodera (2006) found that the cooling in the equatorial lower stratosphere and upper troposphere during SSW could lead to an enhancement of convective activity near the tropical Southern Hemisphere $\left(10^{\circ} \mathrm{S}\right.$-equator) and a suppression near the tropical Northern Hemisphere $\left(5-10^{\circ} \mathrm{N}\right)$. Kuroda (2008) also suggested that the tropical convection tends to be enhanced during SSW. The variations of zonal wind have also been noticed (Pancheva et al., 2008; Yuan et al., 2012). Recently, Chandran and Collins (2014) studied the global effects of SSW on winds and found the eastward acceleration below $40 \mathrm{~km}$ and between 60 and $100 \mathrm{~km}$, and westward acceleration within $40-60 \mathrm{~km}$ in the lower latitudes (equator $-20^{\circ} \mathrm{N}$ ). However, there are few studies on the response of the Kelvin waves to the SSWs, so no definite conclusions are drawn about the mechanisms through which the Kelvin waves and the SSWs are connected.

In the present paper, we extended the research by Kodera (2006) to study the features of Kelvin wave activity variability, especially around the TTL region, during the SSWs and attempted to present an explanation of the relationship between Kelvin wave and SSWs. To fulfill our goals, a case study was made on an exceptionally large SSW event in 2009 to investigate the typical features and a composite analysis was applied to reveal the common features of the Kelvin wave variability during the SSW events.

The data sets used in this study are described in Sect. 2. Section 3 shows the background changes during the SSW events. Section 4 presents the variations of Kelvin waves during SSW events. Discussions of several questions which arose in the previous sections are shown in Sect. 5, and conclusions are summarized in Sect. 6.

\section{Data}

In this study, we adopted the European Center for Medium Range Weather Forecasting (ECMWF) reanalysis (ERAInterim) temperature and wind fields data. We also validated the results by the Constellation Observing System for Meteorology, Ionosphere, and Climate (COSMIC) satellites' temperature data.

The ERA-Interim reanalysis is a gridded data set assimilating the observations and numerical weather prediction model output from 1979 to present (Dee et al., 2011). The ERA-Interim provides data of many atmosphere parameters (e.g. temperature, wind fields, humidity, etc.) for 37 standard pressure levels at $6 \mathrm{~h}$ intervals. In this study, we adopted the temperature, zonal wind, meridional wind, and vertical velocity data with a spatial resolution of $2.5^{\circ} \times$ $2.5^{\circ}$ (latitude $\times$ longitude). Since our study focuses on the stratosphere and upper troposphere and to make it convenient to validate our results with the COSMIC Level 2 
temperature data, we restricted the altitude range of the data within $200-5 \mathrm{hPa}(11-37 \mathrm{~km}$, roughly). A more detailed description and the whole data sets can be obtained from the ECMWF website (http://www.ecmwf.int/en/ research/climate-reanalysis/era-interim).

The COSMIC Level 2 temperature profiles have a vertical resolution of $0.1 \mathrm{~km}$. These data were provided by University Corporation of Atmospheric Research (UCAR) and processed by COSMIC Data Analysis and Archive Center (CDAAC). COSMIC constellation is constructed by six Low Earth Orbit (LEO) satellites with a $72^{\circ}$ inclination and was launched in April 2006. COSMIC provides profiles of temperature, pressure, and humidity in the neutral atmosphere, and its excellent latitudinal coverage made it particularly useful for studying the global phenomena (Anthes et al., 2008). The altitude range of the temperature profiles is from near surface to $40 \mathrm{~km}$, while we focus on the region above $10 \mathrm{~km}$ because of the inaccuracy in the lower altitude due to the humidity contributions. The accuracy of the temperature profiles above $10 \mathrm{~km}$ is sub-Kelvin (Schreiner et al., 2007; Wang and Alexander, 2009).

Besides, we also used the OLR data obtained from the National Oceanic and Atmospheric Administration (NOAA) (Liebmann and Smith, 1996) as a proxy for tropical convections.

\section{The tropical background during the SSW events}

\subsection{The SSW events identification}

During the SSW events, the zonal mean temperature in the stratosphere of the polar region increases rapidly within a few days, meanwhile, the eastward zonal mean polar zonal wind decreases, and the SSW events can be identified as major ones if the eastward zonal mean polar zonal winds reverse to westward and minor ones do not reverse. With the long temporal coverage of ERA-Interim from 1979 to present, we identified the SSW events which occurred from 1979 to 2013 based on the features described above.

Previous studies (Matsuno, 1971; Manney et al., 2009) showed that the enhancement of extratropical planetary waves forcing is the cause of the SSW events. According to Andrews et al. (1987), the relationship between zonal mean zonal wind tendency $\left(\frac{\partial \bar{u}}{\partial t}\right)$ and the extratropical planetary wave forcing can be approximately expressed as

$$
\frac{\partial \bar{u}}{\partial t}=f \bar{v}^{*}+\nabla \cdot F,
$$

where $\bar{u}$ is the mean zonal wind, $f$ is the Coriolis parameter, $\bar{v}^{*}$ is the mean residual meridional wind, overbars denote the zonal mean. $f \bar{v}^{*}$ represents the Coriolis force due to residual circulation, and $\nabla \cdot F$ is the divergence of the Eliassen-Palm $(E-P)$ flux which represents the planetary wave forcing. Similar to Kodera (2006), we choose the zonal mean zonal

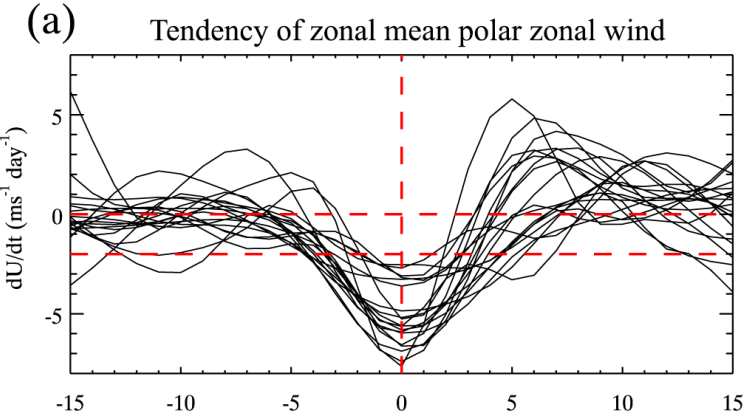

(b) Zonal mean polar temperature and zonal wind

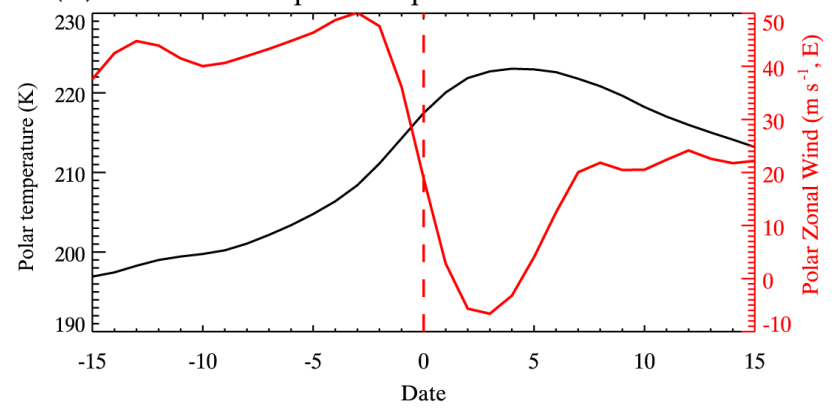

Figure 1. Time series of (a) the tendency of zonal mean zonal wind of each identified SSW event, and (b) the zonal mean polar temperature (black) and zonal wind (red, positive eastward) averaged by all the identified SSW events, at $10 \mathrm{hPa}$ averaged between 60 and $90^{\circ} \mathrm{N}$. The vertical dashed line indicates the central date (day 0) when the decreasing rate of zonal winds for each SSW event is the largest. The horizontal dashed lines in (a) correspond to 0 and $-2 \mathrm{~m} \mathrm{~s}^{-1}$ day $^{-1}$.

wind tendency to measure the strength of interaction between the planetary wave and the polar vortex during each selected SSW event. Using the ERA-Interim Reanalysis zonal wind data, the tendencies of zonal mean zonal wind at $10 \mathrm{hPa}$ averaged between 60 and $90^{\circ} \mathrm{N}$ are calculated, and the day with the maximum deceleration is regarded as the central date (day 0). In this study, we focus on the SSW events which occurred in Arctic winter (December-February), and the central dates of the identified SSW events are listed in Table 1. Note that we excluded several events (e.g. the four events in 2008) since they are too close to be distinguished as individual events.

Figure 1a shows the time tendencies of these 19 identified events. It is clearly seen that the maximum deceleration values of zonal mean polar zonal wind of these events can exceed $-2 \mathrm{~m} \mathrm{~s}^{-1}$ day $^{-1}$ (positive eastward). The variations of zonal mean polar temperature and zonal wind at $10 \mathrm{hPa}$, which are averaged by all the identified events mentioned above from day -15 to day 15 , are shown in Fig. 1b. The common features of the SSWs are well represented in the averaged event: the polar temperature during the composite event starts to increase from $203 \mathrm{~K}$ on day -8 and peaks (about $222 \mathrm{~K}$ ) on day 3 , while the polar eastward zonal wind 
starts to decrease from $50 \mathrm{~m} \mathrm{~s}^{-1}$ on day -3 and minimizes (about $-5 \mathrm{~m} \mathrm{~s}^{-1}$ ) on day 3 .

\subsection{Tropical Changes during the SSW Events}

\subsubsection{The 2009 SSW event}

The 2009 event is documented as the strongest Arctic SSW event since 1979 (Harada et al., 2009), which would help to elucidate the typical features that our study focuses on. To study the variations in the tropical region during the SSW event, we analyzed the variations of extratropical planetary wave forcing, tropical temperature, tropical vertical velocity between 200 and $5 \mathrm{hPa}$ using the ERA-Interim data, and the equatorial convection using OLR data. The temporal variations of those anomalous variables from day -15 to day 15 during the 2009 event are presented in Fig. 2. The anomalies mentioned in the present study are calculated as the departure from the 31 -day mean from day -15 to day 15 . The anomalies are further linearly detrended to remove the effects due to long timescale oscillations (e.g. QBO). We also applied a 5-day running mean to suppress day-to-day fluctuations. All these variables except vertical velocity are shown in both physical values (color shades) and values normalized by standard deviation $(\sigma)$. The tropical vertical velocity is just shown in a normalized value because the physical value could vary more than two orders from the bottom to the top of the altitude range.

Figure 2a shows the eddy heat flux averaged between 40 and $70^{\circ} \mathrm{N}$, a region where the extratropical wave forcing is located. Since the zonal mean eddy heat flux of the planetary waves $\overline{v^{\prime} T^{\prime}}\left(v^{\prime}\right.$ and $T^{\prime}$ are perturbations of meridional wind and temperature due to planetary waves) is proportional to the vertical component of $E-P$ flux $F_{z}=\frac{\rho_{0} f_{0}}{\partial \theta_{0} / \partial z} \overline{v^{\prime} \theta^{\prime}}$ (where $\rho_{0}$ and $\theta_{0}$ are the reference density and potential temperature, respectively. $\theta^{\prime}$ is the perturbation of potential temperature due to planetary waves. $z$ is the altitude, see Andrews et al., 1987), the $\overline{v^{\prime} T^{\prime}}$ can be chosen as an indicator of extratropical wave forcing. We subtracted planetary scale wave components with zonal wave numbers $k$ smaller than 4 (i.e. $k=1,2,3$ ) (Hitchcock and Simpson, 2014) from extratropical meridional wind and temperature field, which were obtained from ERA-Interim Reanalysis between 200 and $5 \mathrm{hPa}$, to calculate the eddy heat flux. The overbar denotes zonal mean. Positive anomalies, which represent the enhancement of extratropical wave forcing, appear around day -10 and become larger than $1 \sigma$ around day -8 . Just as expected, the extratropical wave forcing peaks around day 0 . Corresponding to the enhancement of wave forcing, the SSW event in the polar region is initiated.

Besides SSWs, the enhancement of extratropical wave forcing would simultaneously alter the hemispherical meridional circulation which, in turn, causes some changes in the tropical region (Garcia, 1987; Randel, 1993; Holton et al., 1995; Randel et al., 2002; Yoshida and Yamazaki, 2011). So
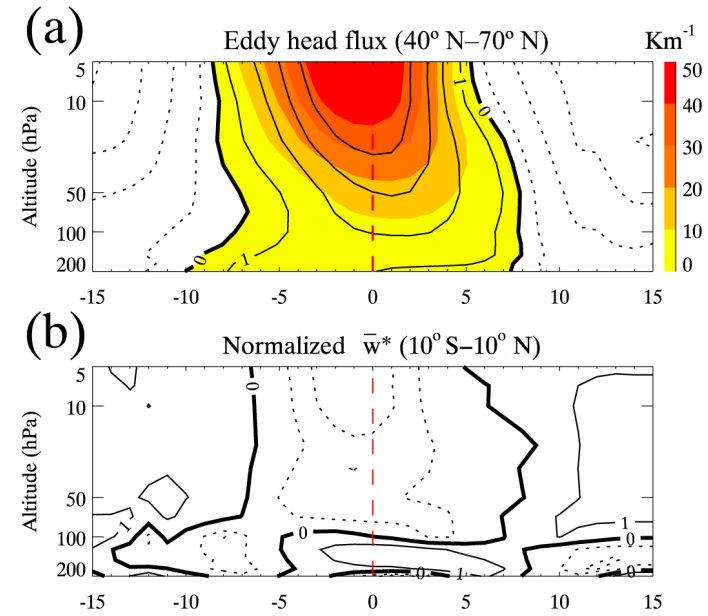

(c) Zonal mean anomalous temperature $\left(10^{\circ} \mathrm{S}-10^{\circ} \mathrm{N}\right) \mathrm{K}$
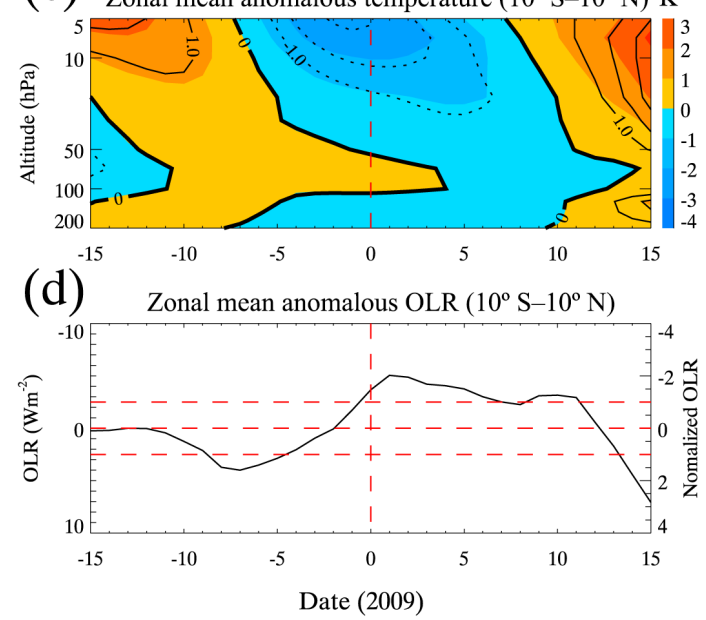

Figure 2. The time altitude cross section of zonal mean (a) anomalous eddy heat flux averaged between 40 and $70^{\circ} \mathrm{N}$ shown in physical value (color shades) and normalized value (contours), (b) the normalized anomalous vertical velocity averaged between $10^{\circ} \mathrm{S}$ and $10^{\circ} \mathrm{N}$, and (c) the anomalous temperature averaged between $10^{\circ} \mathrm{S}$ and $10^{\circ} \mathrm{N}$ shown in physical value (color shades) and normalized value (contours). (d) The time series of anomalous OLR data averaged between $10^{\circ} \mathrm{S}$ and $10^{\circ} \mathrm{N}$. The normalized values are calculated as anomalies normalized by standard deviation $(\sigma)$. The red vertical lines indicate day 0 , the central date of the 2009 SSW event. The dashed horizontal lines in (d) indicate zero and $\pm 1 \sigma$.

we calculate the vertical velocity of the residual circulation in the tropical region $\left(10^{\circ} \mathrm{S}-10^{\circ} \mathrm{N}\right)$, which would be helpful to illustrate the corresponding features associated with the wave forcing induced meridional circulation therein (Andrews et al., 1987; Garcia, 1987). According to Andrews et al. (1987), the vertical velocity of residual circulation $\left(\bar{w}^{*}\right)$ is defined as $\bar{w}^{*} \equiv \bar{w}+(a \cos \phi)^{-1}\left(\cos \phi \overline{v^{\prime} \theta^{\prime}} / \overline{\theta_{z}}\right)_{\phi}$, where the overbars denote the zonal mean, subscripts denote partial differentiation, $a$ is the Earth radius, $\phi$ is latitude. The unit of the vertical velocity outcome is converted to $\mathrm{Pa} \mathrm{s}^{-1}$ when we calculate the normalized value since the results are presented in pres- 
sure coordinate. It is obviously shown that the upward vertical velocity anomalies larger than $1 \sigma$ mainly appear around day -5 in the stratosphere above $100 \mathrm{hPa}$ (Fig. 2b; note that the upward anomalous vertical velocity is negative in pressure coordinate), corresponding to the extratropical wave forcing enhancement. The enhanced upward anomalous vertical velocity represents the enhanced upwelling of the air masses in the tropical region, which could be induced by the meridional circulation. Following the increase of the tropical upwelling, a clear cooling of the tropical region $\left(10^{\circ} \mathrm{S}-\right.$ $10^{\circ} \mathrm{N}$ ) appears around day -5 (Fig. 2c). The temperature decreases about $4 \mathrm{~K}$ within 5 days and the negative anomalies are mainly located above $50 \mathrm{hPa}$. The cooling also occurs in the upper troposphere but the negative temperature anomalies vary less than $1 \sigma$. The variation of the temperature is affected by both of the vertical velocity and the thermal forcing (Andrews et al., 1987; Kuroda and Kodera, 2004). However, since the wave forcing frequency is faster than that of the thermal forcing (Garcia, 1987; Randel et al., 2002), the response of tropical temperature, especially in the stratosphere, to the wave forcing could be regarded as adiabatic, which means the temperature tendency and vertical velocity in the tropical region during the SSW are roughly related as $\frac{\partial \bar{T}}{\partial t} \approx-\Gamma \bar{w}^{*}, \Gamma$ is a factor of static ability. When the upwelling in the tropical region enhances, the air masses ascend and expand adiabatically, as a result, the tropical temperature in the stratosphere would decrease.

Figure $2 \mathrm{~d}$ depicts the time series of the zonal mean anomalous OLR (the lower OLR data correspond to higher convective activity, note that the $y$ axis is reversed so that the peak and/or valley of the time series corresponds to the peak and/or valley of the convection). The anomalous OLR starts to decrease rapidly from about day -8 and the negative value less than $1 \sigma$ appear on day -1 . The OLR reaches the minimum on day 1 , after which the tropical convection decreases and returns to the pre-warming level around day 10 (absolute value less than $1 \sigma$ ). The variation of OLR data suggests that the zonal mean convection in the equatorial region is enhanced during the SSW event. Previous studies suggested that the convection enhancement is connected to the enhanced upwelling through convergence of air mass and water vapor in the troposphere during SSW events (Collimore et al., 2003; Eguchi and Kodera, 2007). The enhancements of the tropical convection which occurred during the SSW events, implying more equatorial waves could be excited during SSWs, have also been reported by previous works (Kodera and Yamada, 2004; Kodera, 2006, 2008).

\subsubsection{Composite event}

The composite analysis is applied to study the common features of tropical variations during the SSW events. The composite event is averaged by all the identified events listed in Table 1 except for the 2009 event, which would undermine the robustness of the composite analysis if it is included. To
Table 1. Central date of the identified SSW events.

\begin{tabular}{cl}
\hline Year of the SSW events & Central date \\
\hline 1981 & 29 January \\
1984 & 18 February \\
1984 & 29 December \\
1987 & 17 January \\
1989 & 18 February \\
1990 & 9 February \\
1992 & 11 January \\
1995 & 19 January \\
1998 & 14 December \\
1999 & 23 February \\
2001 & 25 December \\
2003 & 16 January \\
2004 & 1 January \\
2006 & 22 January \\
2007 & 21 February \\
2009 & 22 January \\
2010 & 23 January \\
2012 & 12 January \\
2013 & 4 January \\
\hline
\end{tabular}

reveal the robustness of the composite results, a Student $t$ test is applied. The Student $t$ value is defined as follows:

Student $t=x /\left(\sigma / n^{1 / 2}\right)$,

where $n$ is the number of the samples included in the composite analysis, $x$ is the mean over the 18 samples, and $\sigma$ is the standard deviation as mentioned above. In this study, the values corresponding to a $95 \%$ significance level for onesided and two-sided tests are 1.73 and 2.10 , respectively. So the Student $t$ absolute values exceeding 2 are chosen to illustrate the significant part.

As shown in Fig. 3, the variations of an extratropical eddy heat flux, tropical vertical velocity of residual circulation, tropical temperature, and tropical OLR in the composite event shared almost the same features with those in the 2009 SSW event, indicating that the tropical variations are identical during the SSW events. Though the enhancements of tropical convection during the SSW events is valid, the connection between the enhanced residual circulation and the tropical convection might be questioned since the tropical changes of vertical velocity and temperature are significant mainly above $50 \mathrm{hPa}$, which is consistent to the previous studies (Ueyama et al., 2013; Abalos et al., 2014). In fact, recent studies by Kodera et al. (2015) have stated that the influence of the enhanced residual circulation could penetrate downward into the troposphere through the change of cloud formation during SSW events, further strengthening the equatorial convection. Besides, our composite results are consistent with the results of Kodera (2006).

Briefly summarizing the descriptions of this section, we know that the extratropical wave forcing causes the SSW in the polar region, and simultaneously drives the meridional 


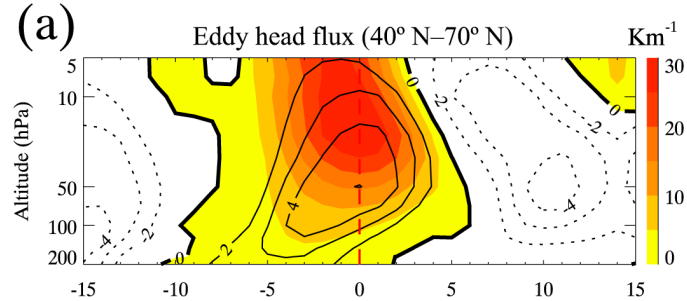

(b)

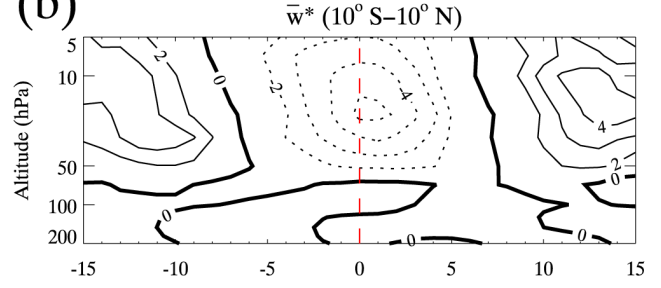

(c)

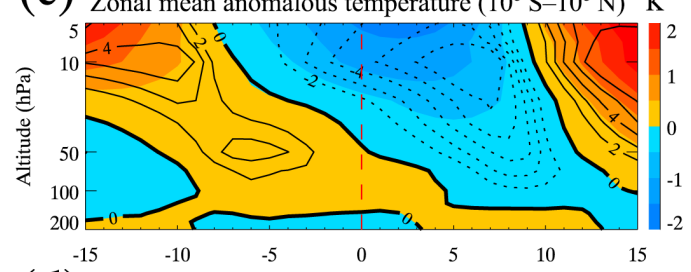

(d)

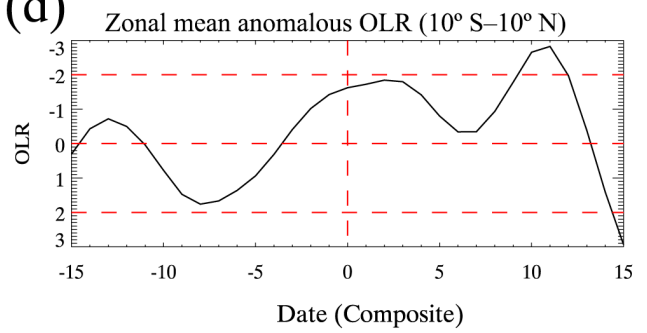

Figure 3. The time-altitude cross section of zonal mean (a) anomalous eddy heat flux averaged between 40 and $70^{\circ} \mathrm{N}$ shown in physical value (color shades) and $t$ values (contours), (b) the $t$ values of anomalous vertical velocity averaged between $10^{\circ} \mathrm{S}$ and $10^{\circ} \mathrm{N}$, and (c) the anomalous temperature averaged between $10^{\circ} \mathrm{S}$ and $10^{\circ} \mathrm{N}$ shown in physical value (color shades) and $t$ value (contours). (d) The time series of anomalous OLR data averaged between $10^{\circ} \mathrm{S}$ and $10^{\circ} \mathrm{N}$ shown in $t$ values. The red vertical lines indicate the central date of the composite SSW event. The dashed horizontal lines in (d) indicate zero and \pm 2 .

circulation. The enhanced meridional circulation, in turn, induces the tropical upwelling, which causes the temperature decrease in stratosphere and upper troposphere in the tropical region. The influence of the enhanced tropical upwelling would also penetrate downward into the troposphere and enhance the tropical convection, which would further excite more equatorial waves. Thus, we may conclude that the SSW event in the polar region and the tropical changes, especially the enhancement of equatorial waves, are two individual results due to the extratropical planetary wave forcing.

\section{Kelvin waves during the SSW events}

\subsection{Extraction of Kelvin waves}

In this study, we focus on the variations of Kelvin wave during the SSWs and the certain connections between them. To extract Kelvin wave components, we applied a space-time spectral analysis to the temperature perturbations $T^{\prime}$, which are calculated as departure from zonal mean daily temperature at each height for each day. As described by Ern et al. (2008), in the space-time spectral analysis, the temperature perturbations are first divided into symmetric and antisymmetric components with respect to the equator:

$$
\begin{aligned}
T^{\prime}(\phi) & =0.5 \times\left[T^{\prime}(\phi)+T^{\prime}(-\phi)\right]+0.5 \times\left[T^{\prime}(\phi)-T^{\prime}(-\phi)\right] \\
& =T_{\mathrm{s}}^{\prime}(\phi)+T_{\mathrm{a}}^{\prime}(\phi),
\end{aligned}
$$

where $\phi$ is latitude, $T^{\prime}{ }_{\mathrm{s}}(\phi)$ and $T^{\prime}{ }_{\mathrm{a}}(\phi)$ are symmetric and antisymmetric components of the temperature perturbations, respectively. At fixed latitude, the temperature perturbations are a function of longitude and time. Then, we apply a 2-D Fourier transform to obtain wavenumber-frequency spectra of the symmetric/antisymmetric temperature components. It should be noted that, in order to apply 2-D Fourier transform mentioned above, the data grids must be even. So, before calculating temperature perturbations $T^{\prime}$, the uneven COSMIC data $\left(15^{\circ} \mathrm{S}-15^{\circ} \mathrm{N}\right)$ are first binned into non-overlapped $5^{\circ} \times 15^{\circ}$ (latitude $\times$ longitude) grid cells with temporal resolution of 1 day. The temperature data averaged within one grid cell are regarded as the data at the grid center. Thus, we obtain COSMIC temperature data on five latitude bands centering on $10^{\circ} \mathrm{S} / \mathrm{N}, 5^{\circ} \mathrm{S} / \mathrm{N}$ and $0^{\circ}$ and each band has 24 grids in longitude. The ERA-Interim Reanalysis data are binned into the same latitude bands with COSMIC data while the longitude width of each grid cell is kept original (i.e. $2.5^{\circ}$ ). Since the Kelvin waves are large-scale components (mostly with zonal wavenumber $s=1,2,3$ ), the different longitude width of the two data sets will not have much of an effect on the result.

Temperature field of Kelvin waves is in the symmetric mode (Andrews et al., 1987; Tindall et al., 2006), and according to the dispersion relation (Ern and Preusse, 2009; Matsuno, 1966), Kelvin wave components with different wave numbers and frequencies are extracted from the symmetric spectra by band pass filtering. The filtering region of Kelvin wave in the spectra is recognized by the different equivalent depth (Wheeler and Kiladis, 1999), corresponding to different phase speed of Kelvin waves $\left(c_{x}=\sqrt{g h_{e}}\right.$, where $g$ is the gravitational acceleration). Since the altitude range in our study is restricted to the upper troposphere and lower stratosphere, according to Alexander et al. (2008), the band of within this altitude range is restricted to $8 \mathrm{~m}<h_{e}<240 \mathrm{~m}$ (about $9 \mathrm{~m} \mathrm{~s}^{-1}<c_{x}<50 \mathrm{~m} \mathrm{~s}^{-1}$ ).

The spectral analysis and extraction method described above are applied to the ERA-Interim reanalysis data and COSMIC data in a SSW duration, from day -15 to day 15 
(a) Spectral of $\mathrm{T}$ (10hpa)

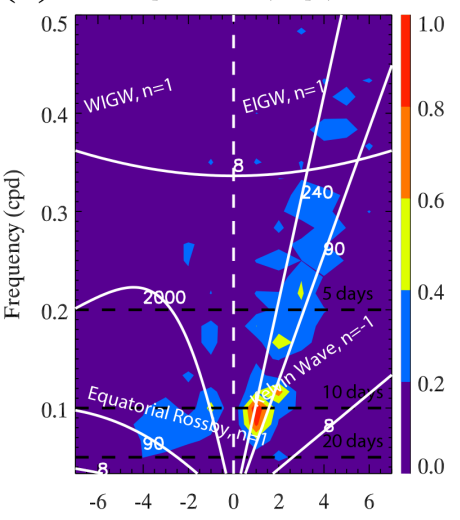

(d)

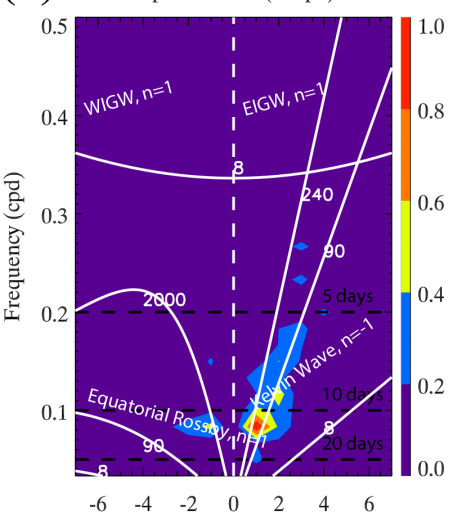

(g)

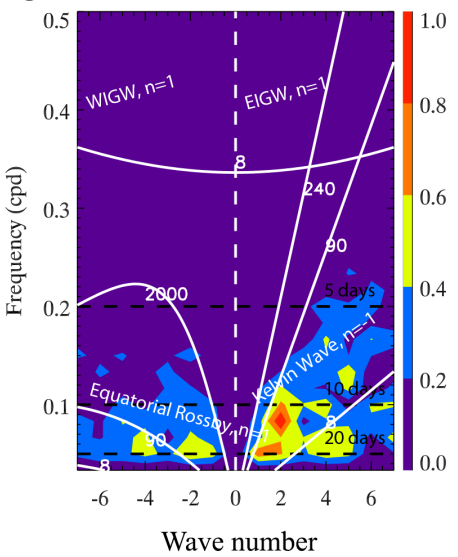

(b)

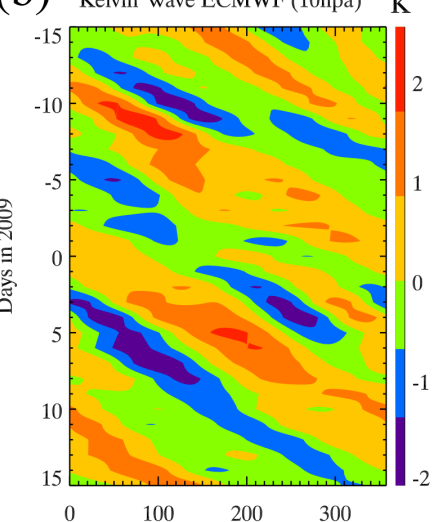

(e)

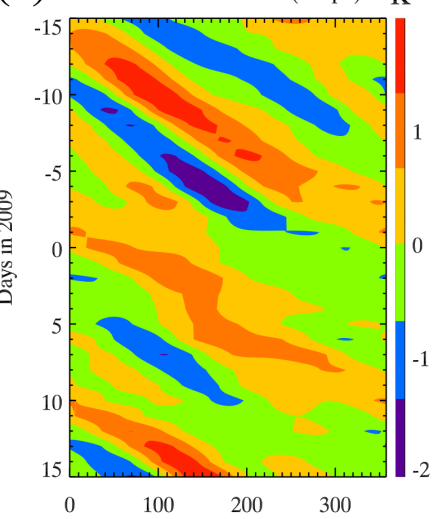

(h)

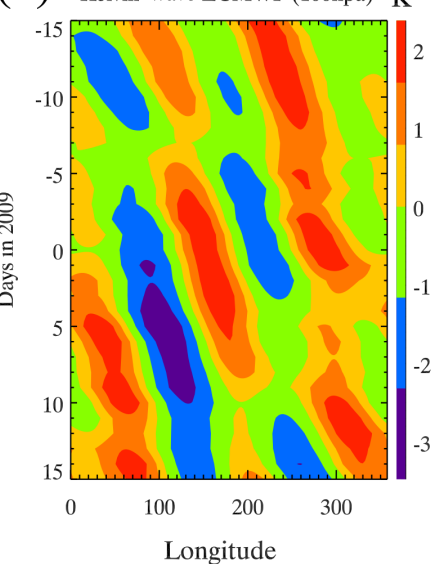

(c)

Kelvin wave COSMIC (32km) K

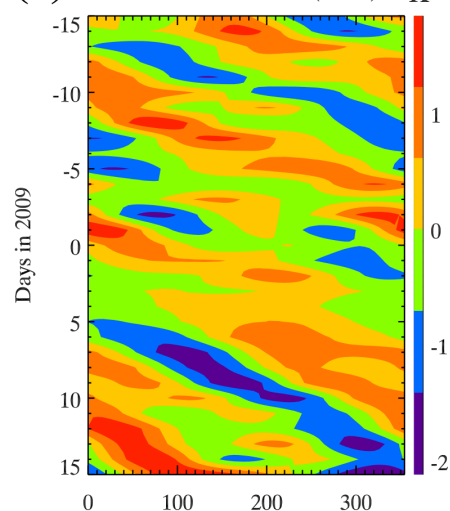

(f)

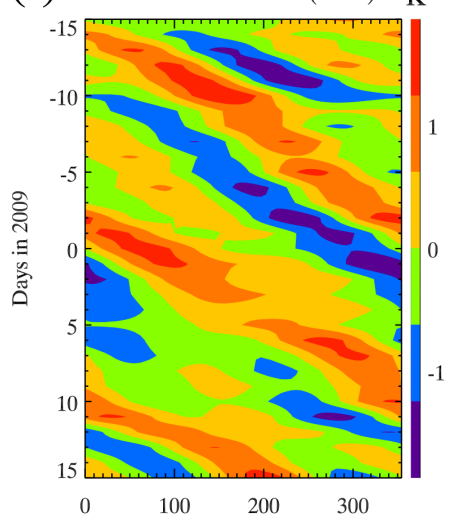

(i)

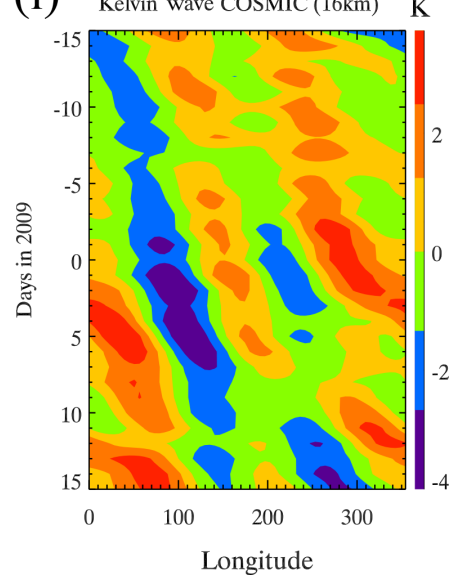

Figure 4. The normalized wavenumber and/or frequency spectra of the symmetric temperature perturbations using ERA-Interim reanalysis data (a, d, g), the time-longitude cross section of Kelvin wave variances derived from ERA-Interim data (b, e, h) and COSMIC data (c, f, i) at $100 \mathrm{hPa}$ (roughly $16 \mathrm{~km}$, bottom), $50 \mathrm{hPa}$ (roughly $21 \mathrm{~km}$, middle), and $10 \mathrm{hPa}$ (roughly $32 \mathrm{~km}$, top) during the $2009 \mathrm{SSW}$ event. The white curves in $(\mathbf{a}),(\mathbf{d})$ and $(\mathbf{g})$ represent the dispersion relation of different wave components for different equivalent depth.

in 2009, and the results of the equatorial band are shown in Fig. 4: the wavenumber-frequency spectra of the symmetric temperature perturbations using ERA-Interim data (Fig. 4a, $\mathrm{d}$ and $\mathrm{g}$ ), the time-longitude cross section of Kelvin wave variances derived from ERA-Interim data (Fig. 4b, e, and h) and COSMIC data (Fig. 4c, f and i) at $100 \mathrm{hPa}$ (roughly
$16 \mathrm{~km}$, bottom), $50 \mathrm{hPa}$ (roughly $21 \mathrm{~km}$, middle), and $10 \mathrm{hPa}$ (roughly $32 \mathrm{~km}$, top). The white curves in the Fig. 4a, d, and $\mathrm{g}$ represent the dispersion relations of different wave components for different equivalent depth. It is clear that Kelvin wave dominates the symmetric spectra in both the upper troposphere and stratosphere (Fig. 4a, d, and g). The spec- 
tral peaks of Kelvin wave in the upper troposphere are constrained to $8 \mathrm{~m}<h_{e}<90 \mathrm{~m}\left(9 \mathrm{~m} \mathrm{~s}^{-1}<c_{x}<30 \mathrm{~m} \mathrm{~s}^{-1}\right)$ while shift to higher frequencies and equivalent depths (i.e. phase speeds) in the stratosphere. This phenomenon could be explained by that Kelvin waves with higher frequencies and phase speeds could propagate to higher altitude more easily (Salby et al., 1984). Kelvin wave variances extracted by these two data sets are very similar both in the upper troposphere and stratosphere (Fig. $4 \mathrm{~b}$, e, and $\mathrm{h}$ and $4 \mathrm{c}$, f, and i, respectively), which means that the result of ERA-Interim reanalysis data could reproduce most of the primary features of the realistic Kelvin waves.

\subsection{Variation of Kelvin waves}

\subsubsection{The 2009 event}

In this section, we studied the variation of Kelvin waves during SSW events. Since zonal wind in the tropical region affects the propagation of the Kelvin waves, we first present the variation of zonal mean anomalous zonal wind in the 2009 event averaged between $10^{\circ} \mathrm{S}$ and $10^{\circ} \mathrm{N}$ (Fig. 5a). To illustrate the variations more clearly, we present both physical values (color shades) and the normalized values (black contours). It is obviously shown that the eastward anomalies (positive value) appeared in stratosphere within the SSW duration. The eastward anomalies larger than $1 \sigma$ in the stratosphere first appeared around day -5 at $5 \mathrm{hPa}$ and peaked around day -3 . From the Eq. (1) described in Sect. 3.1, we know that the variation of zonal wind is affected by both Coriolis torque and the wave forcing. While in the tropical region (especially the equatorial region), the Coriolis force is too weak. Thus, the enhancements of westerly anomalies mentioned above are mainly caused by the tropical wave forcing. As the eastward propagating Kelvin waves are the dominant wave components in the tropical region, the Kelvin wave could contribute greatly to the enhancement of tropical eastward zonal wind anomalies.

Figure $5 \mathrm{~b}$ depicts the temporal variation of Kelvin wave strength averaged between $10^{\circ} \mathrm{S}$ and $10^{\circ} \mathrm{N}$ from day -15 to day 15 in 2009. The strength of Kelvin wave is expressed as $\frac{1}{2}{\overline{T^{\prime}}}_{\mathrm{KW}}^{2}$, where $T_{\mathrm{KW}}^{\prime}$ is the variance of Kelvin wave extracted from temperature field, overbar denotes zonal mean. Note that the physical values of Kelvin wave strength (color shades) are shown in non-detrended form while the normalized values are shown in detrended form to represent the significant enhancements (positive) or suppressions (negative). It is noticeable that enhancement of Kelvin wave appeared around day -8 , when the tropical convection started to increase (see Fig. 2d), indicating that the Kelvin waves started to be activated due to the strengthened tropical convection. The Kelvin waves near $100 \mathrm{hPa}$ were relatively strong during the whole SSW duration with two apparent peaks appearing around day -7 and day 4 , respectively. Corresponding to the two peaks near $100 \mathrm{hPa}$, two peaks of Kelvin wave (a) Variation of zonal wind anomalies $\left(10^{\circ} \mathrm{S}-10^{\circ} \mathrm{N}\right) \mathrm{m} \mathrm{s}^{-1}$

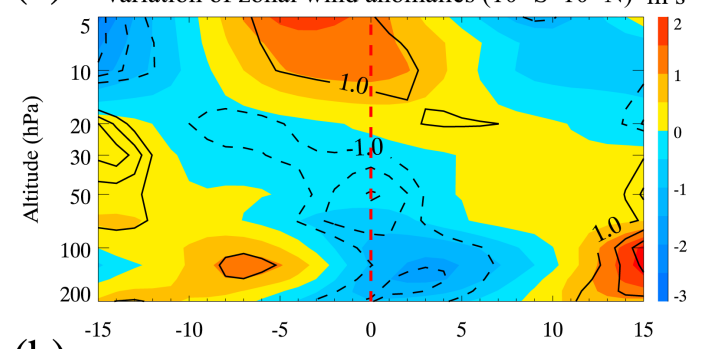

(b) Variation of Kelvin wave strength $\left(10^{\circ} \mathrm{S}-10^{\circ} \mathrm{N}\right) \mathrm{K}^{2}$

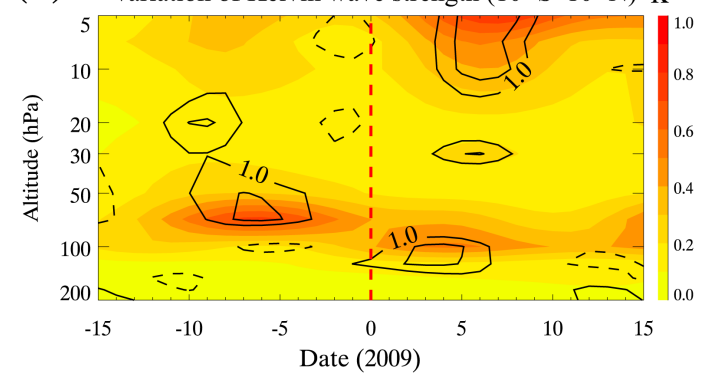

Figure 5. The time-altitude cross section of (a) the anomalous zonal mean zonal wind averaged between $10^{\circ} \mathrm{S}$ and $10^{\circ} \mathrm{N}$, and (b) the strength of Kelvin waves averaged between $10^{\circ} \mathrm{S}$ and $10^{\circ} \mathrm{N}$. The red vertical lines indicate day 0 (22 January), the central date of the 2009 SSW event. All of the variables above are presented both in physical value (color shades) and anomalous values normalized by standard deviations (black contours). Solid contours indicate positive values of normalized anomalous values while dashed contours indicate negative values.

also appeared in the stratosphere above $20 \mathrm{hPa}$. An apparent suppression appeared above $30 \mathrm{hPa}$ around day 0 . Then, it arouses a question here regarding which factor, the variations of wave source or the wind filtering, contributes more to the Kelvin wave variability.

To elucidate the question above, we studied the longitudinal distribution of Kelvin wave strength and its relation with zonal wind and tropical convection. The definition of Kelvin wave strength here is the same with that mentioned above, but without zonal mean (i.e. $\frac{1}{2} T_{\mathrm{KW}}^{\prime 2}$ ).

Figure 6 presents the time evolution of Kelvin wave strength (color shades), zonal wind (black contours), and OLR (black lines) during the 2009 SSW event. Before the SSW event (day -15 , Fig. 6a), the Kelvin wave was relatively weak and the convection (low values of OLR) localized around the western Pacific $\left(100-150^{\circ}\right.$ E). From day -15 to day 10 , the total strength of the Kelvin waves became much stronger as the zonal mean convection started to enhance (see Figs. $2 d$ and $5 b$ ), the convection in the western Pacific was intensified, and enhancement of Kelvin wave strength emerged in this region, corresponding to the convection peak (Fig. 6b). The correspondence between the peaks of Kelvin wave and convection in the western Pacific also occurred on day -5 (Fig. 6c). 
(a)

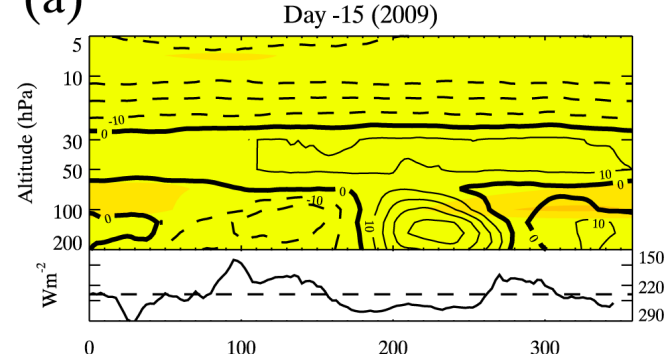

(c)

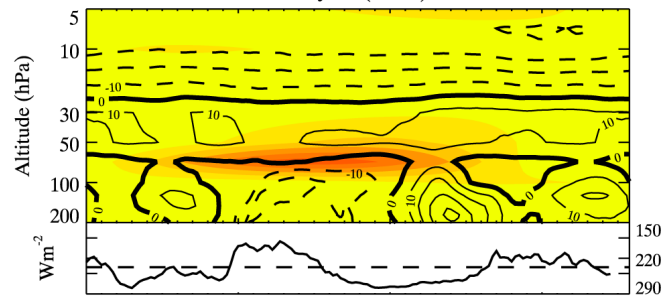

(e)

100

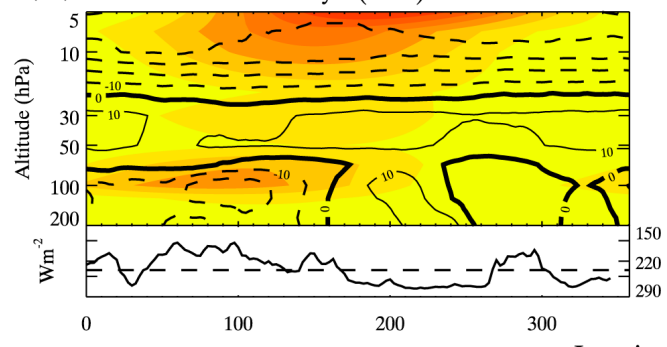

(b) Day -10 (2009)

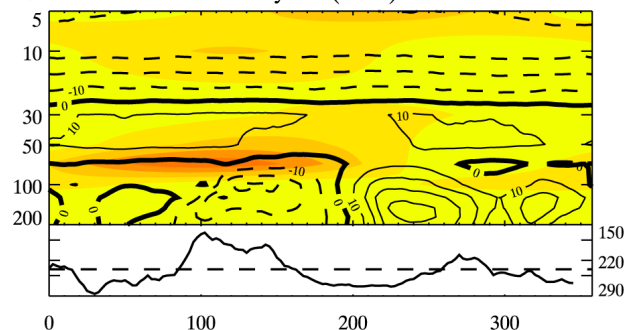

(d)

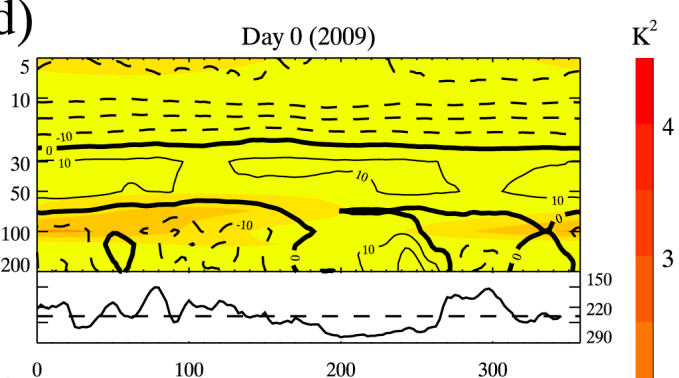

(f)

100

Day 10 (2009)

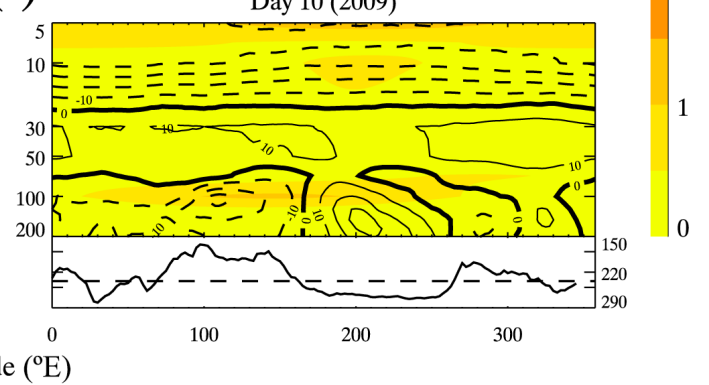

Figure 6. The longitude-altitude cross sections of Kelvin wave strength (color shades), zonal wind (black contours), and the longitudinal series of OLR (black solid lines) at day -15 (a), -10 (b), -5 (c), 0 (d), 5 (e), 10 (f) of the 2009 SSW event. All the characters above are averaged between $10^{\circ} \mathrm{S}-10^{\circ} \mathrm{N}$. The solid contours indicate eastward wind and the dashed ones indicate the westward. Bold contours indicate the zero wind. The data are smoothed by a 5-day running mean. The dashed black lines indicate the zonal mean OLR averaged from day -15 to day 15 .

On the central date of SSW event (day 0), the Kelvin wave strength became relatively weaker compared to day -5 because the convection around the western Pacific decayed. It is noticeable that the convection around South America (around $300^{\circ} \mathrm{E}$ ) intensified, and the longitudinal distributions of the Indo-Pacific convection on the equator became more zonally symmetric. Yoshida and Yamazaki (2011) suggested that the zonal extension of tropical convection was linked to decrease of heating by vertical convergence of vertical heat flux in the tropical uppermost troposphere. It seems that the variation of Kelvin waves in Fig. 5b is more related with the localized convection of the Indo-Pacific region.

As we suggested that the tropical convection contributes more to the Kelvin wave activity during an SSW event, the results presented in Figs. 5b and 2d may seem to be controversial. It is noticeable that the enhancement of zonal mean Kelvin wave activity appeared around day -10 to day -5 (Fig. 5b), when the zonal mean convection was not that significant (zonal mean convection just started to increase, and OLR anomalies were still positive, Fig. 2d). But around day 0 , when the peak of zonal mean convection appeared, the Kelvin wave became relatively weaker both around TTL and in the stratosphere. In fact, the enhancement of tropical convection first occurred around day -10 in the IndoPacific region (Fig. 6). Although the zonal mean convection was stronger around day 0 than what it was around day -10 , the convection in the Indo-Pacific region decayed. Since the longitudinal distributions of Kelvin wave activity and OLR shown in Fig. 6 suggest that the Kelvin wave activity corresponds to localized Indo-Pacific convection, that is the reason of the correspondence between enactments of zonal mean Kelvin wave and zonal mean convection.

After the central day, the Kelvin wave strength enhanced around day 5 but with a westward shift of peak compared to that before day 0 , corresponding to the convection enhancement of the western Pacific. When approaching the end of 
the SSW duration, the longitudinal distribution of zonal wind filed and convection tended to recover to the pre-warming conditions.

\subsubsection{The composite event}

The composite analysis is also applied to investigate the temporal variation of tropical zonal wind and Kelvin waves (Fig. 7). Besides the physical values (color shades), we also plotted the Student $t$ value to represent the significant part.

The temporal variation of zonal mean anomalous zonal wind in the composite event averaged between $10^{\circ} \mathrm{S}$ and $10^{\circ} \mathrm{N}$ is shown in Fig. 7a. Significant zonal wind variation mainly occurred above $50 \mathrm{hPa}$. Enhanced eastward anomalies appeared from day -10 to day -3 , corresponding to the enhancement of Kelvin wave (Fig. 7b). This phenomenon indicates that the enhancement of anomalous westerly zonal wind in the stratosphere is a common feature during SSW events, and the enhancement mainly occurs before the central date of SSW events. Our result is consistent with Chandran and Collins (2014).

The variation of Kelvin wave strength during the composite event is generally the same with that in the 2009 . Kelvin wave in the upper troposphere was relatively strong all through the SSW duration. Two enhancements occurred in the stratosphere above $20 \mathrm{hPa}$, one showed up on day 8 , while the other on day 11 . The gaps between the two enhancements are relatively longer than those in the 2009 event, which are 10 days all through upper troposphere to stratosphere. Around day 0, significant suppression appeared above $50 \mathrm{hPa}$.

The results of longitudinal distribution of Kelvin wave, zonal wind anomalies, and OLR in the composite event are shown in Fig. 8. Note that only the Kelvin wave strength with confidence level higher than $95 \%$ is shown. The wind field is composited by the anomalous value as departure from zonal mean and expressed in $t$ value because wind anomalies are more meaningful than zonal wind since the QBO phases during these SSW events were different. Similar to the 2009 event, localized convection lied within the Indo-Pacific region first intensified on day -10 . While approaching day 0 , the convection in the western Pacific decreased, and the longitudinal distributions OLR became more zonally symmetric. Alexander et al. (2008) once reported that the convective coupling with Kelvin waves was not always clear, while the correspondence between Kelvin waves and convection peaks in our results, especially near the TTL, suggested that Kelvin wave strongly coupled with tropical convection during SSW events. In the stratosphere above $100 \mathrm{hPa}$, where the Kelvin wave freely propagated (Alexander et al., 2008), strong Kelvin wave would be found near the zero wind lines, indicating that the upward propagation of the Kelvin waves is also affected by wind filtering.

As a summary, we know that the Kelvin waves coupled with localized Indo-Pacific convection during SSW events.

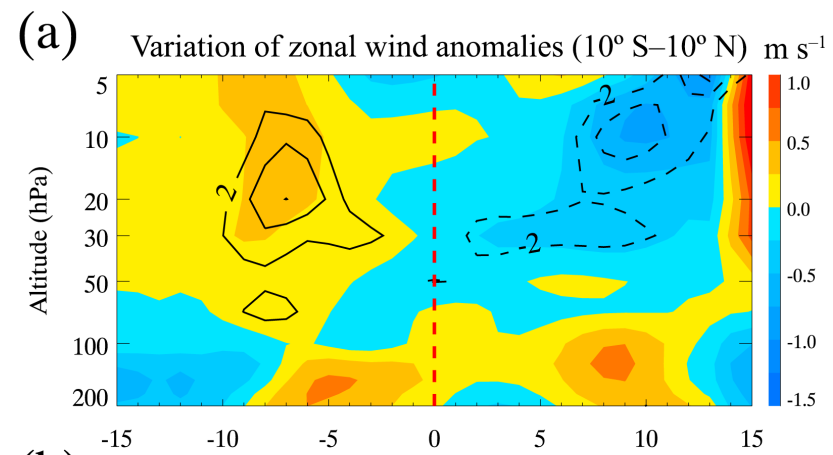

(b) Variation of Kelvin wave strength $\left(10^{\circ} \mathrm{S}-10^{\circ} \mathrm{N}\right) \mathrm{K}^{2}$

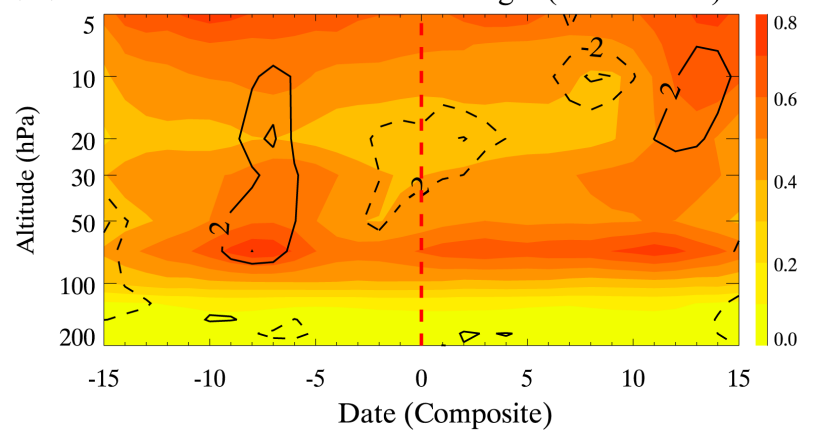

Figure 7. The time-altitude cross section of (a) the anomalous zonal mean zonal wind averaged between $10^{\circ} \mathrm{S}$ and $10^{\circ} \mathrm{N}$, and (b) the strength of Kelvin waves averaged between $10^{\circ} \mathrm{S}$ and $10^{\circ} \mathrm{N}$. The red vertical lines indicate day 0 of the composite event. All of the variables above are presented both in physical value (color shades) and $t$ values (black contours). Solid contours indicate positive $t$ values of anomalous values while dashed contours indicate negative $t$ values.

Kelvin waves could interact with zonal wind in the stratosphere of the tropical region and contribute to driving the eastward zonal wind anomalies in the Indo-Pacific region above $30 \mathrm{hPa}$ during SSW events. On the other hand, the vertical propagation of Kelvin wave is also affected by the zonal wind field through wind filtering.

\section{Discussion}

The previous sections present the variability of tropical background and Kelvin wave activities during SSW events, from which arose several questions.

The peaks of Kelvin wave activity in the stratosphere may seem to be strange as they do not always correspond to the eastward anomalies of zonal wind, but note that we presented the zonal wind anomalies instead of zonal wind in Figs. 5a and 6a. Taking the 2009 event for example, though the eastward anomalies of zonal wind appeared around day 0 in the stratosphere, the zonal mean zonal wind was easterly throughout the whole duration of the SSW event, which was a favorable condition for the propagation of Kelvin wave. So, 

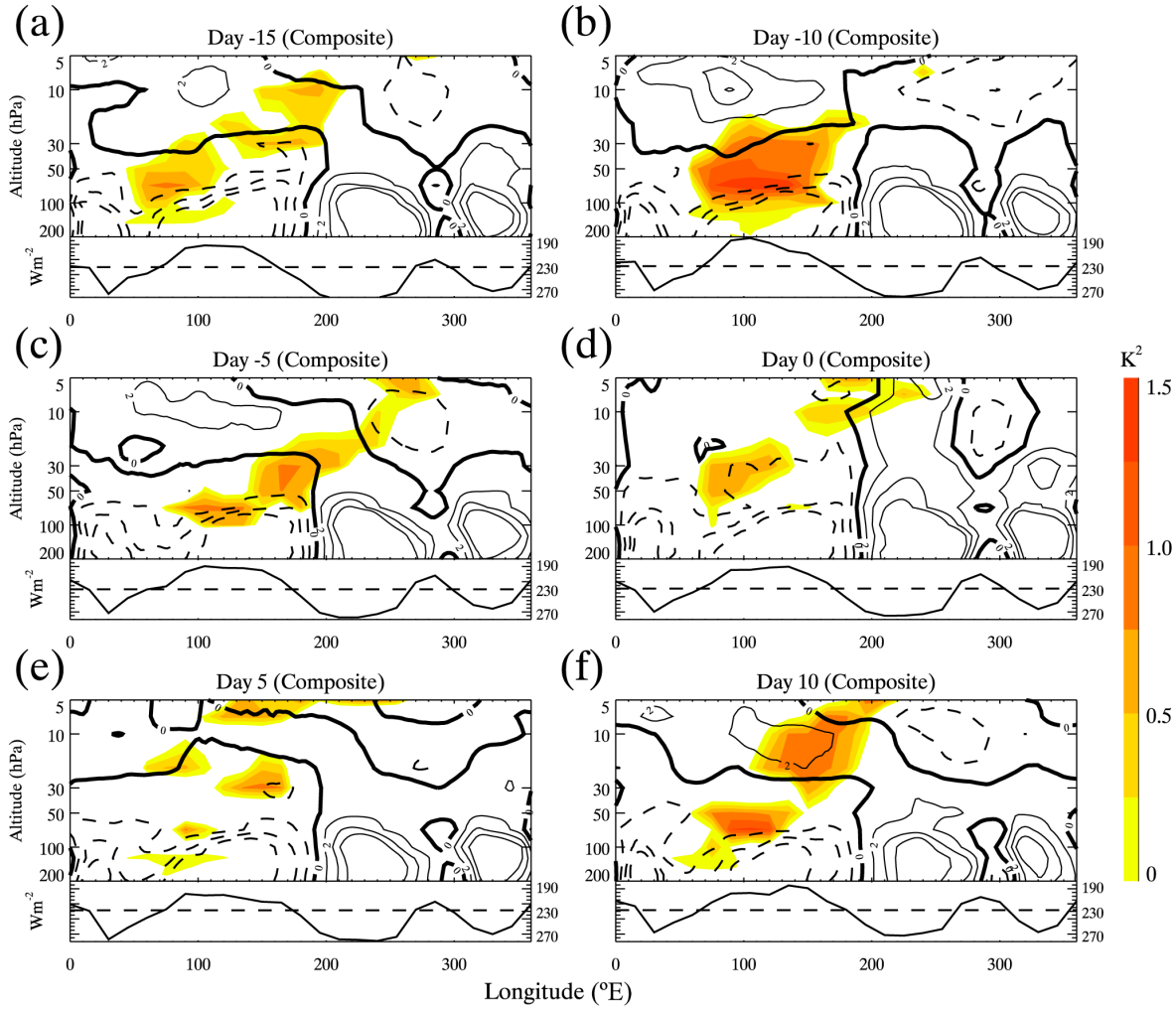

Figure 8. The longitude-altitude cross sections of Kelvin wave strength (color shades) shown only those corresponding to the significance level higher than $95 \%$, zonal wind (black contours), and the longitudinal series of OLR (black solid lines) at day -15 (a), -10 (b), -5 (c), 0 (d), 5 (e), 10 (f) of the composite SSW event. All the characters above are averaged between $10^{\circ} \mathrm{S}$ and $10^{\circ} \mathrm{N}$. The solid contours indicate eastward wind anomalies and the dashed ones indicate the westward shown in $t$ value. Bold contours indicate the zero wind. The data are smoothed by a 5-day running mean. The dashed black lines indicate the $95 \%$ significance level of the averaged OLR of the composite event.

the Kelvin wave in the stratosphere may not necessarily correspond to the eastward zonal wind anomalies.

In Sect. 4, we reported that Kelvin wave may contribute to driving the equatorial eastward anomalies of zonal wind during the SSW events, from which arose a question, i.e. to what extent would Kelvin wave contribute to the changes of zonal wind? To quantify the Kelvin waves forcing, we calculate the vertical gradient of the vertical flux of horizontal momentum, i.e. $F_{\mathrm{KW}}=\frac{\partial \overline{u^{\prime} w^{\prime}}}{\partial z}$, where $u^{\prime}$ and $w^{\prime}$ are the zonal wind and vertical velocity perturbations due to Kelvin waves retrieved from ERA-Interim reanalysis data, the overbar denotes the zonal averaging. The Kelvin wave signatures derived from the vertical velocity data, whose accuracy may be questionable due to the difficulty of detection, were compared with those derived from temperature field. The Kelvin wave signatures are clear in the vertical velocity field, and the frequencies are consistent with those in the temperature field (not shown). The relative contributions of Kelvin waves forcing are expressed as ratio with respect to the total zonal acceleration (i.e. $F_{\mathrm{KW}} / U_{t}$ ). To avoid the abrupt transition caused by the sparse pressure levels when calculating $F_{\mathrm{KW}}$, the $\overline{u^{\prime} w^{\prime}}$ and zonal wind $U$ obtained from the original pres- sure levels are interpolated by spline interpolation to [200], 190, [175], 162.5, [150], 137.5, [125], 112.5, [100], 90, 80, [70], 65, 60, [50], 45, 40, [30], 25, [20], 15, [10], 8, [7], 6, and [5] hPa (with vertical resolutions of $0.5 \mathrm{~km}$ below $50 \mathrm{hPa}$ and $1 \mathrm{~km}$ above, roughly); the brackets represent the original pressure levels. Furthermore, a 3-day running mean is applied to smooth the interpolated data.

Figure 9 shows the altitude-time cross sections of the percentage of total zonal wind acceleration due to Kelvin wave forcing (color shades) calculated from ECMWF reanalysis data during 2009 SSW event (Fig. 9a) and the composite SSW event (Fig. 9b), the anomalous equatorial zonal wind (physical values presented in Figs. 5a and 7a) are over plotted. During the 2009 SSW event, peak Kelvin wave accelerations were generally observed when the westward anomalies (black dashed contours) started to decrease or when the eastward anomalies (black solid contours) started to increase. The Kelvin wave acceleration constituted between 5 and $30 \%$ of the total zonal wind acceleration in the stratosphere, while in the upper troposphere, that range turned into 10 and $60 \%$. Two bulks of enhancement appeared at $20 \mathrm{hPa}$ and right above $200 \mathrm{hPa}$ around day 5 , accordant to the en- 

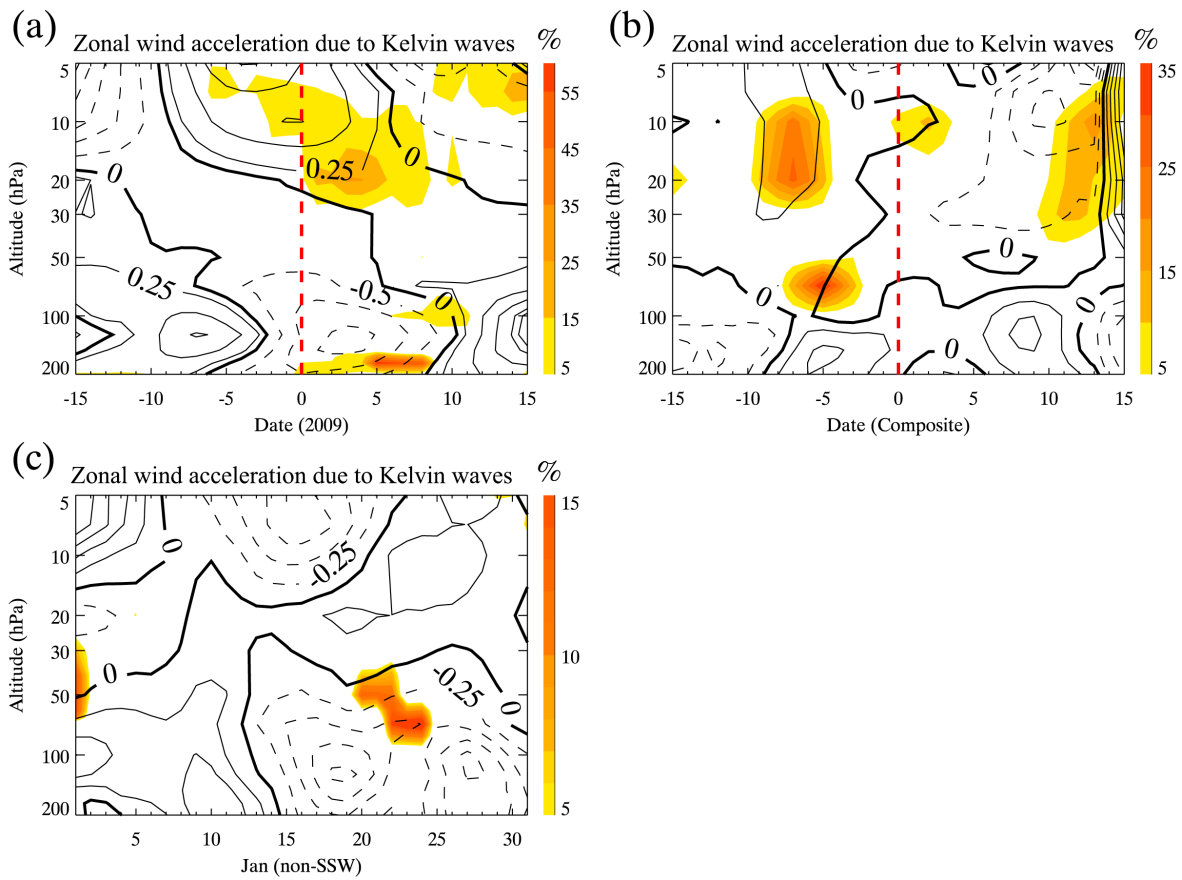

Figure 9. Altitude time cross section of relative contributions of Kelvin wave acceleration to zonal wind acceleration during (a) 2009 SSW event, (b) the composite event, and (c) January without SSWs derived from ECMWF data. The relative contributions are presented in percent, and only positive values are shown. The tropical zonal wind anomalies of each event are overplotted, solid contours represent eastward anomalies, the dashed contours represent westward. Bold contours represent zero wind.

hancement of Kelvin waves (see Fig. 5b). The phenomena above confirmed that, Kelvin wave contributed prominently to the equatorial eastward zonal wind anomalies during the 2009 SSW event.

Similar pattern of Kelvin wave acceleration described above emerged in the composite event. In our study, we neglected the different QBO phases during the SSW events, which could also affect the Kelvin wave accelerations. Because the timescales of the variations of zonal wind and Kelvin wave strength during SSW events (generally within 1 month) are much shorter than QBO. The composited result showed that the Kelvin wave contribution was significant above $100 \mathrm{hPa}$ and the averaged Kelvin wave contribution ranged from 5 to $35 \%$. The result confirms that the Kelvin wave is one of the main contributors to the equatorial zonal wind changes during SSW events.

We also calculated the Kelvin wave acceleration during mid-winters without SSW events. Since it is impossible to define day 0 during winters without SSW, we chose several Januaries without SSW (1982, 1983, 1988, 1991, and 2011) to generally represent the non-SSW mid-winters. The averaged result is shown in Fig. 9c. Distribution of Kelvin wave acceleration shows clear differences between SSWs and nonSSWs. The Kelvin wave acceleration during SSWs mainly appears in the stratosphere above $30 \mathrm{hPa}$, while no significant Kelvin wave acceleration appears in that region during non-
SSW winters, indicating the more important role of Kelvin wave in the zonal wind variability during SSWs.

Though Kelvin wave acceleration to eastward zonal wind anomalies is clear and significant during SSWs, however, the Kelvin wave forcing alone is insufficient in driving the equatorial eastward anomalies during SSWs, which suggests that the effects of other types of eastward propagating equatorial waves (e.g. eastward propagating gravity waves) excited by enhanced convection may not be neglected. In short, the mechanisms of the equatorial eastward zonal wind anomalies during SSW events are still complicated, further studies are needed to understand the related factors.

\section{Conclusions}

The tropical background changes as well as the spatial and temporal variability of Kelvin waves during SSW events are investigated by the ERA-Interim reanalysis data, and the results are validated by the COSMIC temperature data.

Our results support the idea that the tropical changes and the SSWs are two results due to the extratropical planetary wave forcing. The enhancement of extratropical planetary wave forcing causes the warming events in the polar region, also enhances the meridional circulation, and then in turn leads to the tropical upwelling. The tropical upwelling induced by the meridional circulation will further cause temperature decrease in the tropical stratosphere and upper tro- 
posphere. The tropical upwelling and cooling would also affect the distribution of mass and water vapor, consequently leading to enhancement of convection in the equatorial region.

Since the tropical convection is the source of equatorial waves, more waves could be excited during SSW events. Eastward anomalies of equatorial zonal wind emerged due to the eastward propagating equatorial waves through dissipation and transmission of momentum during all the identified SSW events. As the most prominent component of equatorial waves, Kelvin waves were also excited when the tropical convection enhanced during the SSW events. The strengthened Kelvin waves made considerable contributions to driving the eastward zonal wind anomalies in the stratosphere. The averaged contributions of Kelvin wave of all these events ranged from 5 to $35 \%$, much larger than in the non-SSW mid-winters. However, averaged values suggest that the Kelvin wave forcing alone is insufficient in driving the equatorial eastward anomalies during the SSW events, and the contributions of other types of eastward propagating equatorial waves should be taken into account.

The longitudinal distribution of Kelvin wave, especially around the TTL layer, corresponded well to the localized Indo-Pacific convection, which suggests that Kelvin wave strongly coupled with localized tropical convection during SSW events. Ryu and Lee (2010) suggested that the TTL in the western tropical Pacific responded to the wave forcing more significantly than the eastern Pacific. It is also interesting that the significant eastward zonal wind anomalies in the stratosphere were mainly distributed within the Indo-Pacific region above $30 \mathrm{hPa}$ (Fig. 8). All these results indicate that more detailed future studies, including observation and highresolution models, should be applied on the Indo-Pacific region in understanding the Kelvin wave variability during SSWs, but it is beyond the scope of this study. Moreover, strong Kelvin wave mainly located near the zero wind lines, which suggests that vertical propagation of Kelvin waves was also affected by the zonal wind field during SSW events.

Acknowledgements. We are grateful to the European Center for Medium Range Weather Forecasting (ECMWF) for providing ERA-Interim reanalysis at http://www.ecmwf.int/en/research/ climate-reanalysis/era-interim/, and University Corporation of Atmospheric Research (UCAR) for providing online data access of http://cdaac-ftp.cosmic.ucar.edu/cdaac/, without charge. This work was jointly supported by the National Basic Research Program of China (grant 2012CB825605), the National Natural Science Foundation of China (through grants 41531070, 41374155 and 41521063) and the Specialized Fund for Comprehensive Study and Evaluation of the Polar Environment (grant CHINARE2015-0203).

The topical editor, C. Jacobi, thanks two anonymous referees for help in evaluating this paper.

\section{References}

Abalos, M., Randel, W. J., and Serrano, E.: Dynamical Forcing of Subseasonal Variability in the Tropical Brewer-Dobson Circulation, J. Atmos. Sci., 71, 3439-3453, doi:10.1175/JAS-D-130366.1, 2014.

Alexander, S. P., Tsuda, T., Kawatani, Y., and Takahashi, M.: Global distribution of atmospheric waves in the equatorial upper troposphere and lower stratosphere: COSMIC observations of wave mean flow interactions, J. Geophys. Res.-Atmos., 113, D24115, doi:10.1029/2008JD010039, 2008.

Andrews, D. G., Holton, J. R., and Leovy, C. B.: Middle atmosphere dynamics, Academic press, San Diego, California, 489 pp., 1987.

Anthes, R. A., Ector, D., Hunt, D. C., Kuo, Y.-H., Rocken, C., Schreiner, W. S., Sokolovskiy, S. V., Syndergaard, S., Wee, T.K., Zeng, Z., Bernhardt, P. A., Dymond, K. F., Chen, Y., Liu, H., Manning, K., Randel, W. J., Trenberth, K. E., Cucurull, L., Healy, S. B., Ho, S.-P., McCormick, C., Meehan, T. K., Thompson, D. C., and Yen, N. L.: The COSMIC/FORMOSAT3 Mission: Early Results, B. Am. Meteorol. Soc., 89, 313-333, doi:10.1175/BAMS-89-3-313, 2008.

Baldwin, M. P. and Dunkerton, T. J.: Stratospheric Harbingers of Anomalous Weather Regimes, Science, 294, 581-584, doi:10.1126/science.1063315, 2001.

Bergman, J. W. and Salby, M. L.: Equatorial Wave Activity Derived from Fluctuations in Observed Convection, J. Atmos. Sci., 51, 3791-3806, doi:10.1175/15200469(1994)051<3791:EWADFF>2.0.CO;2, 1994.

Chandran, A. and Collins, R. L.: Stratospheric sudden warming effects on winds and temperature in the middle atmosphere at middle and low latitudes: a study using WACCM, Ann. Geophys., 32, 859-874, doi:10.5194/angeo-32-859-2014, 2014.

Chang, L. C., Palo, S. E., Liu, H.-L., Fang, T.-W., and Lin, C. S.: Response of the thermosphere and ionosphere to an ultra fast Kelvin wave, J. Geophys. Res.-Space, 115, A00G04, doi:10.1029/2010JA015453, 2010.

Collimore, C. C., Martin, D. W., Hitchman, M. H., Huesmann, A., and Waliser, D. E.: On The Relationship between the QBO and Tropical Deep Convection, J. Climate, 16, 2552-2568, doi:10.1175/1520-0442(2003)016<2552:OTRBTQ>2.0.CO;2, 2003.

Dee, D. P., Uppala, S. M., Simmons, A. J., Berrisford, P., Poli, P., Kobayashi, S., Andrae, U., Balmaseda, M. A., Balsamo, G., Bauer, P., Bechtold, P., Beljaars, A. C. M., van de Berg, L., Bidlot, J., Bormann, N., Delsol, C., Dragani, R., Fuentes, M., Geer, A. J., Haimberger, L., Healy, S. B., Hersbach, H., Hólm, E. V., Isaksen, L., Kållberg, P., Köhler, M., Matricardi, M., McNally, A. P., Monge-Sanz, B. M., Morcrette, J.-J., Park, B.-K., Peubey, C., de Rosnay, P., Tavolato, C., Thépaut, J.-N., and Vitart, F.: The ERA-Interim reanalysis: configuration and performance of the data assimilation system, Q. J. Roy. Meteor. Soc., 137, 553-597, doi:10.1002/qj.828, 2011.

Eguchi, N. and Kodera, K.: Impact of the 2002, Southern Hemisphere, stratospheric warming on the tropical cirrus clouds and convective activity, Geophys. Res. Lett., 34, L05819, doi:10.1029/2006GL028744, 2007.

Eguchi, N. and Shiotani, M.: Intraseasonal variations of water vapor and cirrus clouds in the tropical upper troposphere, J. Geophys. Res.-Atmos., 109, D12106, doi:10.1029/2003JD004314, 2004. 
Ern, M. and Preusse, P.: Wave fluxes of equatorial Kelvin waves and QBO zonal wind forcing derived from SABER and ECMWF temperature space-time spectra, Atmos. Chem. Phys., 9, 39573986, doi:10.5194/acp-9-3957-2009, 2009.

Ern, M., Preusse, P., Krebsbach, M., Mlynczak, M. G., and Russell III, J. M.: Equatorial wave analysis from SABER and ECMWF temperatures, Atmos. Chem. Phys., 8, 845-869, doi:10.5194/acp-8-845-2008, 2008.

Fritz, S. and Soules, S. D.: Large-Scale Temperature Changes in the Stratosphere Observed from Nimbus III, J. Atmos. Sci., 27, 1091-1097, doi:10.1175/15200469(1970)027<1091:LSTCIT>2.0.CO;2, 1970.

Fueglistaler, S., Dessler, A. E., Dunkerton, T. J., Folkins, I., Fu, Q., and Mote, P. W.: Tropical tropopause layer, Rev. Geophys., 47, RG1004, doi:10.1029/2008RG000267, 2009.

Fujiwara, M., Hasebe, F., Shiotani, M., Nishi, N., Vömel, H., and Oltmans, S. J.: Water vapor control at the tropopause by equatorial Kelvin waves observed over the Galápagos, Geophys. Res. Lett., 28, 3143-3146, doi:10.1029/2001GL013310, 2001.

Garcia, R. R.: On the Mean Meridional Circulation of the Middle Atmosphere, J. Atmos. Sci., 44, 3599-3609, 1987.

Gong, Y., Zhou, Q., and Zhang, S.: Atmospheric tides in the lowlatitude $\mathrm{E}$ and $\mathrm{F}$ regions and their responses to a sudden stratospheric warming event in January 2010, J. Geophys. Res.-Space, 118, 7913-7927, doi:10.1002/2013JA019248, 2013.

Harada, Y., Goto, A., Hasegawa, H., Fujikawa, N., Naoe, H., and Hirooka, T.: A Major Stratospheric Sudden Warming Event in January 2009, J. Atmos. Sci., 67, 2052-2069, doi:10.1175/2009JAS3320.1, 2009.

Hitchcock, P. and Simpson, I. R.: The Downward Influence of Stratospheric Sudden Warmings, J. Atmos. Sci., 71, 3856-3876, doi:10.1175/JAS-D-14-0012.1, 2014.

Holton, J. R. and Lindzen, R. S.: An Updated Theory for the Quasi-Biennial Cycle of the Tropical Stratosphere, J. Atmos. Sci., 29, 1076-1080, doi:10.1175/15200469(1972)029<1076:AUTFTQ>2.0.CO;2, 1972.

Holton, J. R., Haynes, P. H., McIntyre, M. E., Douglass, A. R., Rood, R. B., and Pfister, L.: Stratosphere-troposphere exchange, Rev. Geophys., 33, 403-439, doi:10.1029/95RG02097, 1995.

Jin, H., Miyoshi, Y., Pancheva, D., Mukhtarov, P., Fujiwara, H., and Shinagawa, H.: Response of migrating tides to the stratospheric sudden warming in 2009 and their effects on the ionosphere studied by a whole atmosphere-ionosphere model GAIA with COSMIC and TIMED/SABER observations, J. Geophys. Res.-Space, 117, A10323, doi:10.1029/2012JA017650, 2012.

Kawatani, Y., Takahashi, M., Sato, K., Alexander, S. P., and Tsuda, T.: Global distribution of atmospheric waves in the equatorial upper troposphere and lower stratosphere: AGCM simulation of sources and propagation, J. Geophys. Res.-Atmos., 114, D01102, doi:10.1029/2008JD010374, 2009.

Kodera, K.: Influence of stratospheric sudden warming on the equatorial troposphere, Geophys. Res. Lett., 33, L06804, doi:10.1029/2005GL024510, 2006.

Kuroda, Y.: Effect of stratospheric sudden warming and vortex intensification on the tropospheric climate, J. Geophys. Res.Atmos., 113, D15110, doi:10.1029/2007JD009550, 2008.

Kodera, K. and Yamada, K.: Impact of the SH major stratospheric warming on the Hadley circulation: A case study, Pap. Meteorol. Geophys., 54, 111-116, doi:10.2467/mripapers.54.111, 2004.
Kodera, K., Funatsu, B. M., Claud, C., and Eguchi, N.: The role of convective overshooting clouds in tropical stratospheretroposphere dynamical coupling, Atmos. Chem. Phys., 15, 67676774, doi:10.5194/acp-15-6767-2015, 2015.

Kuroda, Y. and Kodera, K.: Role of the Polar-night Jet Oscillation on the formation of the Arctic Oscillation in the Northern Hemisphere winter, J. Geophys. Res.-Atmos., 109, D11112, doi:10.1029/2003JD004123, 2004.

Liebmann, B. and Smith, C. A.: Description of a complete (interpolated) outgoing longwave radiation dataset, B. Am. Meteorol. Soc., 77, 1275-1277, 1996.

Lima, L. M., Alves, E. O., Batista, P. P., Clemesha, B. R., Medeiros, A. F., and Buriti, R. A.: Sudden stratospheric warming effects on the mesospheric tides and 2-day wave dynamics at $7^{\circ} \mathrm{S}, \mathrm{J}$. Atmos. Sol. Terr. Phys., 78-79, 99-107, 2012.

Liu, H. L. and Roble, R. G.: A study of a self-generated stratospheric sudden warming and its mesospheric-lower thermospheric impacts using the coupled TIME-GCM/CCM3, J. Geophys. Res.-Atmos., 107, ACL 15-11-ACL 15-18, doi:10.1029/2001JD001533, 2002.

Manney, G. L., Krüger, K., Pawson, S., Minschwaner, K., Schwartz, M. J., Daffer, W. H., Livesey, N. J., Mlynczak, M. G., Remsberg, E. E., Russell, J. M., and Waters, J. W.: The evolution of the stratopause during the 2006 major warming: satellite data and assimilated meteorological analyses, J. Geophys. Res., 113, D11115, doi:10.1029/2007JD009097, 2008.

Manney, G. L., Schwartz, M. J., Krüger, K., Santee, M. L., Pawson, S., Lee, J. N., Daffer, W. H., Fuller, R. A., and Livesey, N. J.: Aura Microwave Limb Sounder observations of dynamics and transport during the record-breaking 2009 Arctic stratospheric major warming, Geophys. Res. Lett., 36, L12815, doi:10.1029/2009GL038586, 2009.

Matsuno, T.: Quasi-Geostrophic Motions in the Equatorial Area, J. Meteorol. Soc. Jpn., 44, 25-43, 1966.

Matsuno, T.: A Dynamical Model of the Stratospheric Sudden Warming, J. Atmos. Sci., 28, 1479-1494, doi:10.1175/15200469(1971)028<1479:ADMOTS>2.0.CO;2, 1971.

Pancheva, D., Mukhtarov, P., Mitchell, N. J., Andonov, B., Merzlyakov, E., Singer, W., Murayama, Y., Kawamura, S., Xiong, J., Wan, W., Hocking, W., Fritts, D., Riggin, D., Meek, C., and Manson, A.: Latitudinal wave coupling of the stratosphere and mesosphere during the major stratospheric warming in 2003/2004, Ann. Geophys., 26, 467-483, doi:10.5194/angeo-26-467-2008, 2008.

Phanikumar, D. V., Niranjan Kumar, K., and Kumar, S.: Signatures of ultra fast Kelvin waves in low latitude ionospheric TEC during January 2009 stratospheric warming event, J. Atmos. Sol-Terr. Phy., 117, 48-53, doi:10.1016/j.jastp.2014.05.006, 2014.

Plumb, R. A. and Eluszkiewicz, J.: The BrewerDobson Circulation: Dynamics of the Tropical Upwelling, J. Atmos. Sci., 56, 868-890, doi:10.1175/15200469(1999)056<0868:TBDCDO>2.0.CO;2, 1999.

Randel, W. J.: Global Variations of Zonal Mean Ozone during Stratospheric Warming Events, J. Atmos. Sci., 50, 3308-3321, doi:10.1175/1520-0469(1993)050<3308:GVOZMO>2.0.CO;2, 1993.

Randel, W. J. and Wu, F.: Kelvin wave variability near the equatorial tropopause observed in GPS radio occulta- 
tion measurements, J. Geophys. Res.-Atmos., 110, D03102, doi:10.1029/2004JD005006, 2005.

Randel, W. J., Garcia, R. R., and Wu, F.: Time-Dependent Upwelling in the Tropical Lower Stratosphere Estimated from the Zonal-Mean Momentum Budget, J. Atmos. Sci., 59, 2141-2152, doi:10.1175/1520-0469(2002)059<2141:TDUITT>2.0.CO;2, 2002.

Ryu, J.-H. and Lee, S.: Effect of Tropical Waves on the Tropical Tropopause Transition Layer Upwelling, J. Atmos. Sci., 65, 1817-1837, 2010.

Ryu, J.-H., Lee, S., and Son, S.-W.: Vertically propagating Kelvin waves and tropical tropopause variability, J. Atmos. Sci., 65, 1817-1837, 2008.

Salby, M. L., Hartmann, D. L., Bailey, P. L., and Gille, J. C.: Evidence for Equatorial Kelvin Modes in Nimbus7 LIMS, J. Atmos. Sci., 41, 220-235, doi:10.1175/15200469(1984)041<0220:EFEKMI>2.0.CO;2, 1984.

Sathishkumar, S., Sridharan, S., and Jacobi, C.: Dynamical response of low-latitude middle atmosphere to major sudden stratospheric warming events, J. Atmos. Sol. Terr. Phys., 71, 857-865, doi:10.1016/j.jastp.2009.04.002, 2009.

Schreiner, W., Rocken, C., Sokolovskiy, S., Syndergaard, S., and Hunt, D.: Estimates of the precision of GPS radio occultations from the COSMIC/FORMOSAT-3 mission, Geophys. Res. Lett., 34, L04808, doi:10.1029/2006GL027557, 2007.

Suzuki, J., Shiotani, M., and Nishi, N.: Lifetime and longitudinal variability of equatorial Kelvin waves around the tropical tropopause region, J. Geophys. Res.-Atmos., 115, D03103, doi:10.1029/2009JD012261, 2010.

Takahashi, H., Wrasse, C. M., Fechine, J., Pancheva, D., Abdu, M. A., Batista, I. S., Lima, L. M., Batista, P. P., Clemesha, B. R., Schuch, N. J., Shiokawa, K., Gobbi, D., Mlynczak, M. G., and Russell, J. M.: Signatures of ultra fast Kelvin waves in the equatorial middle atmosphere and ionosphere, Geophys. Res. Lett., 34, L11108, doi:10.1029/2007GL029612, 2007.

Thompson, D. W. J., Baldwin, M. P., and Wallace, J. M.: Stratospheric Connection to Northern Hemisphere Wintertime Weather: Implications for Prediction, J. Climate., 15, 1421-1428, doi:10.1175/1520-0442(2002)015<1421:SCTNHW>2.0.CO;2, 2002.

Tindall, J. C., Thuburn, J., and Highwood, E. J.: Equatorial waves in the lower stratosphere. I: A novel detection method, Q. J. Roy. Meteor. Soc., 132, 177-194, doi:10.1256/qj.04.152, 2006.
Ueyama, R., Gerber, E. P., Wallace, J. M., and Frierson, D. M. W. The Role of High-Latitude Waves in the Intraseasonal to Seasonal Variability of Tropical Upwelling in the Brewer-Dobson Circulation, J. Atmos. Sci., 70, 1631-1648, doi:10.1175/JAS-D12-0174.1, 2013.

Venkat Ratnam, M., Tsuda, T., Kozu, T., and Mori, S.: Longterm behavior of the Kelvin waves revealed by CHAMP/GPS RO measurements and their effects on the tropopause structure, Ann. Geophys., 24, 1355-1366, doi:10.5194/angeo-24-13552006, 2006.

Vineeth, C., Pant, T. K., Kumar, K. K., and Sumod, S. G.: Tropical connection to the polar stratospheric sudden warming through quasi 16-day planetary wave, Ann. Geophys., 28, 2007-2013, doi:10.5194/angeo-28-2007-2010, 2010.

Wallace, J. M. and Kousky, V. E.: Observational Evidence of Kelvin Waves in the Tropical Stratosphere, J. Atmos. Sci., 25, 900-907, doi:10.1175/1520-0469(1968)025<0900:OEOKWI>2.0.CO;2, 1968.

Wang, L. and Alexander, M. J.: Gravity wave activity during stratospheric sudden warmings in the 2007-2008 Northern Hemisphere winter, J. Geophys. Res.-Atmos., 114, D18108, doi:10.1029/2009JD011867, 2009.

Wheeler, M. and Kiladis, G. N.: Convectively Coupled Equatorial Waves: Analysis of Clouds and Temperature in the Wavenumber-Frequency Domain, J. Atmos. Sci., 56, 374-399, doi:10.1175/1520-0469(1999)056<0374:CCEWAO>2.0.CO;2, 1999.

Yoshida, K. and Yamazaki, K.: Tropical cooling in the case of stratospheric sudden warming in January 2009: focus on the tropical tropopause layer, Atmos. Chem. Phys., 11, 6325-6336, doi:10.5194/acp-11-6325-2011, 2011.

Yuan, T., Thurairajah, B., She, C.-Y., Chandran, A., Collins, R. L., and Krueger, D. A.: Wind and temperature response of midlatitude mesopause region to the 2009 Sudden Stratospheric Warming, J. Geophys. Res., 117, D09114, doi:10.1029/2011JD017142, 2012.

Zhou, X. and Holton, J. R.: Intraseasonal Variations of Tropical Cold-Point Tropopause Temperatures, J. Climate., 15, 1460-1473, doi:10.1175/1520 0442(2002)015<1460:IVOTCP>2.0.CO;2, 2002. 